\title{
Validation of the Polish version of Satisfaction with Asthma Treatment Questionnaire (SATQ)
}

\author{
Katarzyna Dońka', Krzysztof J. Czarnocki², Andrzej Emeryk ${ }^{3}$ \\ ${ }^{1}$ Chair and Department of Pediatric Nursing, Medical University of Lublin, Lublin, Poland \\ ${ }^{2}$ Chair of Ergonomics, Lublin Polytechnic School, Lublin, Poland \\ ${ }^{3}$ Chair of Lung Diseases and Rheumatology, Medical University of Lublin, Lublin, Poland
}

Adv Dermatol Allergol 2017; XXXIV (1): 77-81

DOI: https://doi.org/10.5114/ada.2017.65625

\begin{abstract}
Introduction: Among the chronically ill there is a tendency for non-compliance with medical recommendations, which is often due to low satisfaction with the offered treatment. Satisfaction with Asthma Treatment Questionnaire (SATQ) is a questionnaire for measuring satisfaction with the inhalation treatment of asthma in patients of more than 18 years of age. SATQ is a standardized tool that has not been previously used in Poland. SATQ consists of 4 domains: efficiency, ease of use, the burdening with asthma treatment and side effects and concerns.

Aim: To validate the Polish language version of SATQ questionnaire and an overall verification of the usefulness of the tool relative to trials from clinical practice.

Material and methods: The degree of difficulty and comprehension of the questions and the reliability and validity of the Polish version of the questionnaire was determined in 67 patients with asthma (mean age: $45.8 \pm 14.3$ years (range maximum - at least 18-65 years). The vast majority of patients in the study group have used the inhalers for more than 1 year and were educated in the field of aerosols management. The resulting scores are calculated by adding up the scores for each question and dividing by the number of questions. The reliability of the questionnaire design was verified using the Spearman rank correlation coefficients between elements and ranges between band assessments and evaluations and overall assessment of quality and patient satisfaction with treatment. Internal consistency and reliability of the tool was assessed using Cronbach's $\alpha$. The values of Cronbach's $\alpha$ were evaluated with respect to the threshold value of 0.70 .

Results: SATQ questionnaire was understandable and easy to fill out for all subjects. The filling time of SATQ was designed as to be within 5-10 min. Cronbach's $\alpha$ was reached on all scales, demonstrating the reliability of the analyzed scale and lack of redundancy.

Conclusions: The Polish version of SATQ questionnaire meets the basic psychometric criteria and can be used to assess satisfaction with the inhalation treatment of asthma.
\end{abstract}

Key words: asthma, patient satisfaction, validation study, questionnaire.

\section{Introduction}

In the recent years, a growing interest in importance of adherence and compliance for the treatment of chronic diseases, including asthma [1-4] has been widely observed. Compliance by patients with asthma treatment has a significant impact on the degree of disease control and the quality of life with the disease (GINA 2014) [2, $5,6]$. A number of studies have shown that among the chronically ill there is a tendency for non-compliance with medical recommendations, which is also due to low satisfaction with treatment $[7,8]$. Satisfaction is a feeling of happiness with the fulfillment of certain expectations, and the emotional state resulting from the achievement of some goal [9]. Satisfaction of treatment will generally be higher, the less the patient needs will detach from the wanted results. With proper treatment in asthma, including education and a partnership between the physician and the patient and his family, one can achieve full control of the disease $[3,7,10,11]$. Proper education also allows the patient for self-control of the disease [12]. It is therefore true to say that "the sick with asthma who know more about their disease, could live longer and better lives". In the course of asthma one emphasizes

Address for correspondence: Katarzyna Dońka, Chair and Department of Pediatric Nursing, Medical University of Lublin, 6 Prof. A. Gębali St, 20-093 Lublin, Poland, phone: +48 8171853 75, e-mail: katarzyna.donka@umlub.pl Received: 1.12.2015, accepted: 27.01.2016. 
the importance of emotional reactions of patients. The importance of emotional factors and the degree of social activity restrictions may be even greater when asthma symptoms are not adequately controlled $[13,14]$. In case of diseases of varying severity when modifying therapy should be done on a regular basis, the active participation of the patient in the therapeutic process should be of vital importance $[12,15]$. The use of an individual treatment plan and effective communication with the patient means the greater acceptance of therapy [12].

The basic method of treatment of patients with asthma is an inhalation therapy. The choice of the method of inhaled drug delivery results from the need of chronic treatment of a disease, ensuring a strong effect of local action and the need to limit systemic effects of the treatment, which ensures aerosol therapy $[7,12,16]$.

\section{Aim}

Satisfaction with Asthma Treatment Questionnaire (SATQ) is standardized, but has not been previously used in Poland, due to the lack of validation. Hence, the aim of the study was validation of the Polish version of SATQ.

\section{Material and methods}

The study group consisted of randomly selected 67 outpatients with chronic asthma of varying degrees of severity.

Inclusion criteria included:

1. Asthma - chronic, light, moderate or severe (data from patient records - a diagnosis of asthma by GINA (2008) [16], requiring daily administration of inhaled drugs;

2. Patients of both sexes aged $18-65$ years;

3. Early education on the proper use of inhalers of an individual type of pressurized metered dose inhaler (pMDI) or dry powder inhaler (DPI; disc, Turbuhaler Aerolizer);

4. Using a pMDI with a short-acting $\beta 2$-agonist and one of the aforementioned DPI inhaled corticosteroids or a combination of a glucocorticosteroid and long-acting $\beta 2$-agonist, for at least the last 3 months before the survey;

5. Agreement for the trial.

The study was conducted in patients treated in two specialized clinics in Lublin and was approved by the Bioethics Committee operating at the Medical University (decision ref. KE0254/121/2009).

\section{Methods}

After obtaining permission from the SATQ copyright holder - AstraZeneca adapted SATQ version was translated into Polish, taking into account the reports in the available sources [17]. Following the recommendations of the MAPI Research Institute [17], the text tool was obtained from English translators - two speakers of the tar- get language. Then, an agreed version of the translation was obtained by comparing the two translated versions. The next step was to reverse translation as agreed, which was made by an interpreter, a native speaker of English, with a fluent command of Polish. The differences to the original version of the questionnaire with a translated version were compared. Differences were corrected by two independent translators. The questionnaire consisted of 26 statements/questions in 4 domains including: efficiency (8 questions) and ease of use (7 questions) of each type of inhaler, burdening with treatment (6 questions) and potential side effects and concerns (5 questions) associated with the inhalation therapy. Pre-defined basic requirements assumed that the questionnaire prepared as a result of adaptation is totally self-fulfilled by the patient and is sufficiently simple, clear and easy to understand and use. The SATQ questionnaire was thus presented to patients during an inspection visit to the outpatient clinic, and then after approx. 2 weeks during another visit - they were given the same questionnaire again to fill out.

Basic demographic data (gender, age, place of residence, education level) and data on disease and treatment (duration of asthma, severity of clinical use inhalers for at least 3 months before the survey) were also collected.

\section{Data analysis}

The data obtained from SATQ questionnaire were analyzed using descriptive statistics methods to verify the variability of the answers and to capture any absence of responses. Tabularizations of data was then carried out, including characteristics of the patients and the responses.

Rating of negative scales was inverted, so that for all the questions a higher score meant a higher level of satisfaction. Factor analysis (principal components with varimax rotation) was used to isolate the shaping level of satisfaction. The score variables were determined by dividing the aggregated ratings of the scale and the number of variables in the compartment.

The resulting score was computed by summing the scores of each question and divided by the number of questions.

Internal consistency and reliability were evaluated using Cronbach's $\alpha$. Reliability (repeatability reviews) was verified using a correlation coefficient of intergroup concordance [18]. $T$ test for dependent samples was used in the evaluation of scores obtained in the first and the second survey. This test was applied both for the individual questions, as well as four domains and overall satisfaction with treatment. In order to assess whether the average difference between the two cycle ratings was different from zero.

The reliability of the questionnaire design was verified using the Spearman rank correlation coefficients 
between the domains and ranges between band assessments and evaluations and a general assessment of patient satisfaction with treatment.

The results of the factor analysis were also used as a pointer to reliability of the design tool.

\section{Results}

The vast majority of patients presented mild asthma - 35 (52.2\%) or moderate one - 30 (44.8\%), only 2 patients had severe one (3\%). The disease duration from diagnosis ranged from 8 months to 35 years, the average was 18 years.

The whole group of patients participated in the adapted psychometric evaluation tool. Demographic data and characteristics of the studied group of patients are all presented in Table 1. After a period of 2 weeks, all patients participating in the study expressed their willingness to complete the questionnaire (secondary test). Patients were treated with different inhalators (Table 2).

Factor analysis was carried out for all SATQ survey questions. The results of internal cohesion and reliability of the test and the primary as well as secondary test results are presented in Table 3.

Cronbach's $\alpha$ value was assessed in relation to the threshold value of 0.70 (criterion proposed in the literature [19-21]) which was achieved for the four domains, demonstrating their reliability and lack of redundancy. Intergroup correlation was used as a measure of reproducibility. The values of the correlation coefficient for the analyzed four scales were at the level of 0.61-0.91. T-test for dependent samples for each question as well as the selected four domains and overall patient satisfaction showed no significant differences for any of the analyzed sections.

Table 4 shows the distribution of the four domains and the overall score (the average of the four scopes). Spearman rank correlation coefficient values between the analyzed domains are summarized in Table 5. Significant correlations were found between the singled domains and the overall level of satisfaction with treatment. The strongest associations were found between satisfaction with the efficiency of treatment and overall satisfaction. The weakest correlation was captured between the extent reflecting the ease of use and side effects and concerns about a particular method of treatment.

\section{Discussion}

Validation of Satisfaction with Asthma Treatment Questionnaire was also conducted in other countries such as Great Britain, France, Greece, the Netherlands, Spain, and Sweden [17]. In literature, however, there are only the results of the validation in the UK and Spain $[22,23]$.
Table 1. Characteristics of patients participating in the study

\begin{tabular}{lc}
\hline Feature & Value \\
\hline Age (min-max) [years] & $45.8(18-65)$ \\
\hline Women/men & $45(67.2 \%) / 22(32.8 \%)$ \\
\hline Duration of illness [years] & $18.0(0.8-35)$ \\
\hline The period of inhalators use: & $1(1.5 \%)$ \\
\hline$\leq 6$ months & $5(7.5 \%)$ \\
\hline $7-12$ months & $26(38.8 \%)$ \\
\hline $1-3$ years & $17(25.3 \%)$ \\
\hline $4-6$ years & $18(26.9 \%)$ \\
\hline$>6$ years & $33(49 \%)$ \\
\hline Professional situation: & $9(12 \%)$ \\
\hline Employed (full time) & $26(39 \%)$ \\
\hline Employed (part time) & \\
\hline Not-employed (student, retired, & \\
\hline unemployed) &
\end{tabular}

Table 2. Inhalation therapy applied by the patients

\begin{tabular}{llc}
\hline Inhalators & N & Percentage \\
\hline pMDI + Disc & 34 & 50.7 \\
\hline pMDI + Turbuhaler & 14 & 20.9 \\
\hline pMDI + Aerolizer & 19 & 28.4 \\
\hline Total & 67 & 100 \\
\hline
\end{tabular}

Table 3. Correlation of the primary test and secondary test, and internal compliance

\begin{tabular}{lcc}
\hline Variable & $\begin{array}{c}\text { Correlation }(r) \\
\text { primary } \\
\text { test/secondary test }\end{array}$ & Cronbach's $\alpha$ \\
\hline Efficiency & 0.87 & 0.79 \\
\hline Ease of use (inhalators) & 0.88 & 0.74 \\
\hline Treatment burdening & 0.61 & 0.71 \\
\hline Side effects and concerns & 0.91 & 0.81 \\
\hline
\end{tabular}

Table 4. The distribution of values of specific domains of SATQ questionnaires

\begin{tabular}{lccc}
\hline Variable & $\begin{array}{c}\text { Medium } \\
\text { value } \pm \text { SD }\end{array}$ & $\begin{array}{c}\text { Positive } \\
\text { results (\%) }\end{array}$ & $\begin{array}{c}\text { Negative } \\
\text { results (\%) }\end{array}$ \\
\hline Efficiency & $6.1 \pm 1.5$ & 62.0 & 5.0 \\
\hline Ease of use (inhalators) & $6.7 \pm 1.2$ & 69.5 & 5.3 \\
\hline Treatment burdening & $4.2 \pm 2.2$ & 37.0 & 9.5 \\
\hline $\begin{array}{l}\text { Side effects } \\
\text { and concerns }\end{array}$ & $3.4 \pm 2.1$ & 42.1 & 32.6 \\
\hline General satisfaction & $5.1 \pm 1.75$ & 52.65 & 13.1 \\
\hline
\end{tabular}


Table 5. Correlations between domains (Spearman's rank correlation coefficients)

\begin{tabular}{lcccc}
\hline Variable & Ease of use & $\begin{array}{c}\text { Burdening with } \\
\text { therapy }\end{array}$ & $\begin{array}{c}\text { Side effects } \\
\text { and concerns }\end{array}$ & $\begin{array}{c}\text { Total } \\
\text { satisfaction }\end{array}$ \\
\hline Efficiency & 0.59 & 0.40 & 0.29 & 0.78 \\
\hline Ease of use (inhalators) & & 0.39 & 0.18 & 0.51 \\
\hline Treatment burdening & & 0.37 & 0.44 \\
\hline Side effects and concerns & & & 0.39 \\
\hline
\end{tabular}

In Poland the validation process was attended by $67.2 \%$ of women and $32.8 \%$ of men, which was comparable in terms of gender studies among patients in the UK and Spain, while a group of people (67) designed to SATQ questionnaire was smaller. The study in the UK encompassed 131 patients with asthma, 66\% of women and $34 \%$ of men. The Spanish team qualified 239 people for the study, including $67.8 \%$ of women and $32.2 \%$ of men.

The mean age of the patients was as follows: 45.8 years (range: 18-65) in Poland, 43.3 (median Q1-Q3, i.e. 29.6-52.9) in Spain. The group surveyed in the UK was the same age as the patients participating in the study in Poland (45 years, range: $18-70$ ).

The disease duration from the time of diagnosis among Polish patients averaged 18 years (range: 0.8-35). For studies in the English population, the average duration of asthma was similar - 17 years (1-60). In contrast, the median time from diagnosis of asthma was 10 years (4-20) among Spaniards.

The surveyed patients had varying degrees of severity of asthma. In the Polish study, $52.2 \%$ of patients had persistent mild asthma, $44.8 \%$ - moderate one and $3 \%$ of patients developed severe disease. In Campbell study, patients had all forms of chronic asthma (mild, moderate, severe), but the author did not submit the percentage distribution. Fernandez collected in his study, patients with episodic asthma (23.0\%), chronic mild (29.3\%), moderate (31.8\%) and severe (15.9\%) types of asthma.

All patients with asthma used inhalers. In Lublin, the largest group (38.8\%) comprised people using the equipment for inhalation from 1 to 3 years. In London the majority of patients (58\%) used the inhalers for more than 6 years. In Spain we were not provided with such data.

More than half of the patients (61\%) living in Poland were professionally active. Among them, 49\% were employed in on a full-time basis, and $12 \%$ worked in on a part-time basis (casual job). Similarly, in the UK, where $54 \%$ of patients with asthma were employed, including $44 \%$ in on a full-time, and $10 \%$ of on a part-time basis. Most, however, were professionally active in Spain (79\%), where $63.2 \%$ were full-time employed and $15.8 \%$ on a part-time basis, but the unemployed formed the smallest group (21\%). In Poland, unemployment affected 39\% and in the UK probably $47 \%$ of patients with asthma, since $3 \%$ of them did not give any answer.

In the present study, the highest Cronbach's $\alpha(0.81)$ was assigned to the domain "side effects and concerns", and a little lower score (0.79) "efficiency". However, in the UK the highest value (0.88) was obtained for the domain "efficiency" and the result 0.71 for the subscale "side effects and concerns." Much like in Spain high values (0.87) were achieved for the domain "efficiency" and "side effects and concerns" assigned a value of 0.71 .

In Poland, the domain of "ease of use" has reached the value of the index of 0.74. However, in the AngloSaxon population the score of 0.82 was comparable to that achieved in Spain - 0.81. The domain "burdening with treatment" in the Polish population reached its lowest score, i.e. 0.71. The same domain had a comparable result in the UK (0.71), while the Spanish study noted the value of 0.60. In the case of the Spanish validation of SATQ, one should notice the fact that the value of Cronbach's $\alpha$ for the domain "burdening with treatment" did not exceed the recommended threshold of 0.70 confirming the reliability of this domain. In the UK and Spain the obtained results indicate a high degree of satisfaction of patients with inhalation therapy and no problem with the use of inhalers. The results obtained in Poland may suggest that a relatively largest group of patients (38.8\%), yet for too short (1-3 years) benefited from the inhalation treatment. Patients could not accept the medical treatment and received it in an excessively intrusive manner in everyday life.

Values of Spearman's rank correlation coefficients between the different domains in our study were comparable to those of Campbell's [22]. In both studies, the strongest correlation was found between "efficiency" and "ease of use": Poland - the UK 0.59-0.55. The weakest compounds discovered between "ease of use" and "side effects and concerns" - in both cases amounted to 0.18 . In contrast, the Spanish team of Fernandez did not carry out such research towards such correlations [23]. The results of their own correlation between domains and overall satisfaction proved to be comparable with results of previous studies. In all three countries (Poland, UK, Spain) there were showed the strongest relationships between domain "efficiency" and overall satisfaction -0.78 ; 0.70; 0.60, respectively.

The results suggest that patients who were able to confirm the efficiency of the treatment of asthma, also had positive feelings of satisfaction with the inhaler and satisfaction of therapy. The Polish study's weakest relationships (0.39) were found between overall satisfaction and "side effects and concerns", which was equivalent 
to the results of the British study. The study by Spanish found the weakest correlation (0.2) between the "burden of treatment" and overall satisfaction.

This allows you to say that neither the possibility of potential side effects or inconvenience associated with the treatment affected the overall satisfaction with inhaled therapy. In the shaping and implementation of new treatments for asthma it is more and more important to have a reliable tool meeting psychometric properties, applicable for routine evaluation of new therapies. One of them is SATQ questionnaire.

The SATQ questionnaire can now be used widely in clinical trials, and it may be taken to trying to further evaluate the discrimination power and sensitivity of the analyzed tools. Moreover, it seems reasonable that the Efficiency of a validated questionnaire was assessed in relation to other questionnaires used to assess satisfaction with treatment, as well as other methods of assessing the efficacy of asthma (e.g. ACT). The SATQ questionnaire should also be assessed in terms of comparisons between groups for patients with different levels of severity of the disease and with an extended range of demographic factors.

\section{Conclusions}

The Polish version of SATQ questionnaire meets the basic criteria of a psychometric tool and can be used to assess satisfaction with the inhalation treatment of asthma.

\section{Conflict of interest}

The authors declare no conflict of interest.

\section{References}

1. Ismaila A, Corriveau D, Vaillancourt J. Impact of adherence to treatment with fluticanose propionate/salmeterol in asthma patients. Curr Med Res Opin 2014; 30: 1417-25.

2. Mäkelä MJ, Backer V, Hedegaard M, et al. Adherence to inhaled therapies, health outcomes and cost in patients with asthma and COPD. Respir Med 2013; 107: 1481-90.

3. Pelaez S, Bacon SL, Aulls MW, et al. Similarities and differences between asthma health care professional and patient views regarding medication adherence. Can Respir J 2014; 21: 221-6.

4. Schatz M, Zeiger RS, Yang SJ, et al. Development and preliminary validation of the Adult Asthma Adherence Questionnaire. J Allergy Clin Immunol Pract 2013; 1: 280-8.

5. Global Strategy for Asthma Management and Prevention, Global Initiative for Asthma (GINA) 2014 (www.ginasthma. org).

6. Small M, Anderson P, Vickers A, et al. Importance of inhalerdevice satisfaction in asthma treatment: real-word observations of physician-observed compliance and clinical/patientreported outcomes. Adv Ther 2011; 28: 202-12.

7. Bjermer L. The importance of continuity in inhaler device choice for asthma and chronic obstructive pulmonary disease. Respiration 2014; 88: 346-52.
8. Mosnaim G, Li H, Martin M, et al. Factors associated with levels of adherence to inhaled corticosteroids in minority adolescents with asthma. Ann Allergy Asthma Immunol 2014; 112: 116-20.

9. Reber AS, Reber ES. Stownik psychologii. Wydawnictwo Naukowe Scholar, Warsaw 2005; 688.

10. Gaude GS, Hattiholi J, Chaudhury A. Role of health education and self-action plan in improving the drug compliance in bronchial asthma. J Family Med Prim Care 2014; 3: 33-8.

11. Small M, Vickers A, Anderson P, et al. The patient-physician partnership in asthma: real-world observations associated with clinical and patient-reported outcomes. Adv Ther 2010; 27: 591-9.

12. Stencel D. Pocketbook directives on treatment and prevention of asthma (in adults and children above 5 years of age). Pocketbook directives for doctors and nurses updated in 2014 . Based on Global Strategy For Asthma Management And Prevention. Copyright 2014 Global Initiative for Asthma. VM Media, Gdańsk 2014 (www.ginasthma.org).

13. Coban H, Aydemir Y. The relationship between allergy and asthma control, quality of life, and emotional status in patients with asthma: a cross-sectional study. Allergy Asthma Clin Immunol 2014; 10: 67.

14. Frieri M, O Connor M, Nassef M. Asthma, stress, and depression in women. Allergy Asthma Proc 2015; 36: 256-61.

15. Education for a partnership in asthma care. National Heart, Lung, and Blood Institute. National Asthma Education and Prevention Program. Expert Panel Report 3: Guidelines for the Diagnosis and Mangament of Asthma. Full Report August 28, 2007; 93-146.

16. Global Strategy for Asthma Management and Prevention, Global Initiative for Asthma (GINA) 2008 (www.ginasthma. org).

17. Linguistic Validation - Introduction. http://www.mapi-institute.com (01.06.2009)

18. Bonett DG. Sample size requirements for estimating intraclass correlations with desired precision. Stat Med 2002; 21: 1331-5.

19. Christmann A, Van Aelst S. Robust estimation of Cronbach's alpha. J Multivar Anal 2006; 97: 1660-74.

20. Cortina JM. What is coefficient alpha? An examination of theory and applications. J Appl Psychol 1993; 78: 98-104.

21. Zumbo BD, Gadermann AM, Zeisser C. Ordinal versions of coefficients alpha and theta for likert rating scales. J Mod Appl Stat Methods 2007; 6: 21-9.

22. Campbell JL, Kiebert GM, Partridge MR. Development of the satisfaction with Inhaled Asthma Treatment Questionnaire. Eur Respir J 2003; 22: 127-34.

23. Fernandez JM, Sanchez CB, Jimenez FJJ, et al. Validation study of the Spanish adaptation of the Satisfaction with Inhaled Asthma Treatment Questionnaire. Arch Bronconeumol 2006; 42: 575-82. 